\title{
POSTOPERATIVE VOMITING: A REVIEW AND PRESENT STATUS OF TREATMENT*
}

\author{
L. E. Simonsen, M.D., C.M., and S. L. VANDEWATER, M.D., F.R.C.P.(C.) $†$
}

Postoperative voMiting remains one of the most frequent complications encountered by the anaesthetist. Although considered no more than a nuisance complication, it can, in certain cases, contribute to more than just discomfort for the patient; it can threaten his very life either immediately through aspiration, or later by serious loss of fluids and electrolytes. It can also add considerable strain on some operation wounds.

After Wang and Barison ${ }^{1}$ further delineated the vomiting centre in 1952, most of the succeeding research and investigation into the control of vomiting has centred about those drugs that have a depressant action on the chemoreceptor trigger zone (C.T.Z.). Out of these investigations have come much valuable and interesting data which the anaesthetist may use as additions to his ever-expanding resources to provide safety and comfort to the surgical patient.

\section{The Vomiting Centre}

Neurophysiologists have long accepted the existence of a vomiting centre. Located in the medulla in the solitary tract and the dorsal part of the lateral reticular formation, it lies in close relationship to many other centres whose functions are associated with the vomiting act such as salivation, spasmodic respiratory movements, and forced inspiration. ${ }^{2}$ Lying dorsolateral to the vagal nuclei and close to the vomiting centre in the area postrema of the floor of the fourth ventricle is an accessory vomiting centre which has been designated as the C.T.Z. The C.T.Z. is a receptor centre, the function of which is to act as a funnel for many afferents arriving centrally from lower levels and to channel these stimuli to the emetic centre which co-ordinates all the nervous and chemical stimuli that converge on it.

The C.T.Z. is not a relay for all afferents, however, since those stimuli which originate in the autonomic nerve endings of the gut, ${ }^{3}$ kidneys, uterus, or the heart ${ }^{4}$ travel via the vagus nerve or sympathetic nervous system, or both, reaching the vomiting centre directly without traversing the C.T.Z. Other stimuli affecting the vomiting centre directly are those arising from $(a)$ hypoxia of the centre, as for example from increased cerebrospinal fluid pressure, or $(b)$ psychic stimuli from the cerebral cortex.

The pathways and origin of stimuli causing vomiting may be summarized as in Table I. It seems reasonable, therefore, that pharmacological efforts to control nausea and vomiting might well be directed at interrupting one of these reflex arcs.

\footnotetext{
'Presented at the Annual Meeting of the Canadian Anaesthetists' Society, Montebello, P.Q., May 8-11, 1961.

fFrom the Department of Anaesthesia, Queen’s University, Kịngston, Ontario.
} 
TABLE I

Causes of Vomiting

1. Indirectly via C.T.Z.

(a) Blood-borne chemical stimuli

(b) Vestibular stimuli (motion sickness)

(c) Certain metabolic and endocrine stimuli producing vomiting of pregnancy

2. Directly via vomiting centre

(a) Stimuli arising from the wall of the gut or heart

(b) Hypoxia of the centre-increased intracranial pressure, anaemia, anoxaemia as in high altitudes

(c) Psychic stimuli-pain, smell, taste, sight

\section{Incidence and Factors Related to Postoperative Vomiting}

Several extensive series of investigations into the incidence of postoperative nausea and vomiting have been reported. The wide range of sults reflect the magnitude of the variations of technique, agents used, ability of the anaesthetist, and dependability of the observer.

Waters $^{5}$ in 1936, in a series of 10,000 cases, reported an over-all incidence of 40.6 per cent. In 1955, Dent ${ }^{6}$ found an incidence of 27.2 per cent and Burt'es and Peckett ${ }^{\top}$ an incidence of 32 per cent. These investigations include all types of surgery and anaesthetic techniques. A control series by Gordon et al..$^{8}$ in 1954 reported an over-all incidence of 41 per cent. Knapp and Beecher ${ }^{9}$ in 1956, using a standard sequence of nitrous oxide, oxygen, and ether for various types of operations, found an incidence as high as 82 per cent whereas Dobkin' ${ }^{10}$ over-all incidence, excluding those with gastric suction, was only 15.5 per cent.

Factors relating to postoperative nausea and vomiting are many and varied. In an excellent review by Belleville, ${ }^{11}$ the most consistent factor noted was the sex difference; women vomited much more commonly than men with no decrease in the female incidence until the eighth decade of life. Men, on the other hand, had a decreasing incidence with age. Boniga ${ }^{12}$ felt that the age group 40 to 60 had the highest incidence. When morphine is used as a premedicant, there is a higher incidence noted than with meperidine.,11 The incidence of nausea and vomiting appears to be highest among those who receive cyclopropane ${ }^{11}$ or ether ${ }^{12}$ and lowest among those who receive thiopentone alone or nitrous oxide and thiopentone. Because of the decreased probability of forcing irritating gases into the stomach, those patients who are intubated vomit less than those who receive their anaesthetic by mask. ${ }^{6,11,13}$ Hypotension during surgery increases the incidence, possibly owing to anoxaemia of the vomiting centre. ${ }^{11}$ The incidence is also directly proportional to the length of anaesthesia, 11,12,14; but Belleville, ${ }^{11}$ on the other hand, felt that the incidence decreased in proportion to the length of postoperative sleeping time. Robbie ${ }^{15}$ found that operations lasting less than half an hour or longer than one hour were followed by a lower incidence than operations lasting between one-half and one hour. The same author felt that with breast operations there was a higher incidence than with operations at other sites. Dent ${ }^{6}$ however, found that more persons having head and neck surgery vomited than those having intra-abdominal or extra-abdominal operations. 'This 
can be expected since the solitary tract that receives afferents from the facial, glossopharyngeal, and vagus nerves is also the site of the vomiting centre. Burtles and Peckett ${ }^{7}$ have shown that the Trendelenburg or reversed Trendelenburg positions were associated with a higher incidence "probably because a large proportion of operations in these positions are carried out in the female, for example, gynaecological abdominal surgery, varicose vein surgery, thyroidectomies and mastectomies." The lowest vomiting incidence was associated with the lithotomy position.

\section{Causes of Postoperative Vomiting.}

1. Circulating anaesthetic agents or break-down products.

2. Hypoxia of the vomiting centre from any cause such as hypotension or increased intracranial pressure.

3. Psychogenic or cortical, including odours, sights, tastes.

4. Gastric irritants, e.g., anaesthetic vapors.

5. Distention or traction of viscera from surgical manipulation.

6. Movements of the patient's head (motion sickness).

7. Emergency patient with a full stomach.

8. Stimulation of vagus, glassopharyngeal, or facial nerves from surgery in the vicinity of these nerves.

9. Idiopathic or undetermined factors: $(a)$ position during surgery, $(b)$ site of surgery, e.g., breast, pelvis, $(c)$ sex and age.

\section{The Role of the Anti-emetics}

In a review of the existing literature of the past decade or so, it appears that most of the investigation into postoperative nausea and yomiting centres about the anti-emetic properties of the antihistamines, phenothiazine derivatives, and other unrelated compounds such as trimethoxybenzamide.

However, a very old drug with anti-emetic properties is one which tends to be lost in the myriad of new compounds: scopolamine.

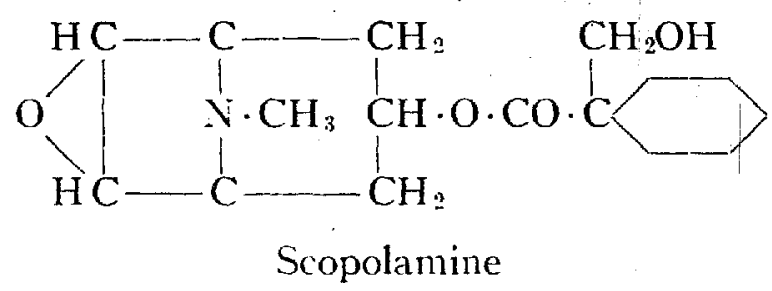

The antinauseant property of scopolamine has been appreciated for many years although the site of action has not been clarified. Its ability to block impulses from the cortex to the medulla ${ }^{16}$ helps support Goodman and Gillman's ${ }^{17}$ opinion that scopolamine's site of action in motion sickness protection is likely cortical or directly on the utricular maculae. It may also be assumed that part of its anti-emetic efficacy may lie in its ability to block vagal impulses to the vomiting centre from the bowel and heart. Because of the number of other antinauseants in common use, and also because of the undesirable side effects 
of the drug such as drowsiness, tachycardia, and visual disturbances in larger doses, it perhaps is not the drug of choice in the prevention or treatment of nausea and vomiting.

When antihistamines were discovered (by accident) to have antinauseant properties, numerous investigations were carried out on a variety of these drugs. Those found to be most useful were dimenhydrinate (Dramamine), 18,19,20,21 diphenhydramine (Benadryl), ${ }^{22,23}$ and cyclizine lactate (Marzine), ${ }^{12,13,24,25}$ Other antihistaminics such as prophenpyridamine (or Trimeton), chlorcyclizine (Perazil), and meclizine (Bonamine) are also listed ${ }^{26}$ as giving significant protection against motion sickness as compared with a placebo but not of sufficient importance to elaborate upon in a review of this nature.
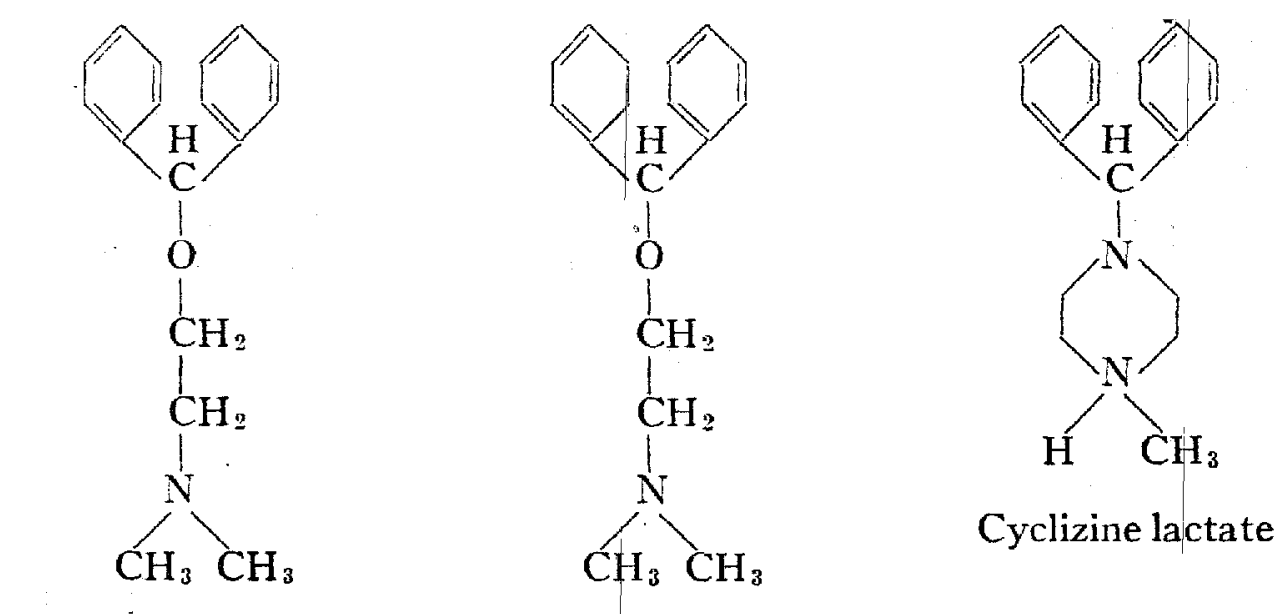

Diphenhydramine

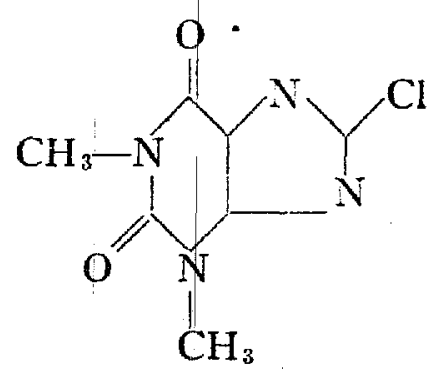

Dimenhydrinate

Although dimenhydrinate differs from diphenhydramine by the addition of 8-chlorotheophylline, the radical contributes nothing to the anti-emetic action of the drug and the two drugs are considered equal in effect. ${ }^{27}$ Following the classical work of Gay and Carliner ${ }^{28}$ into the prevention and treatment of seasickness, dimenhydrinate was investigated by several groups and found to be an effective anti-emetic, with results compared with chlorpromazine, ranging from satisfactory ${ }^{29}$ to good. ${ }^{18}$ As Kulasavage and McCawley ${ }^{30}$ pointed out, however, dimenhydrinate fails to protect against stimuli arising in the stomach, thus sug. gesting that its site of action is elsewhere than on the vomiting centre or on the afferents travelling centrally from the gut. The only significant side effects noted from the use of dimenhydrinate were pain at the site of injection ${ }^{19}$ and occasion. ally prolonged drowsiness. ${ }^{18,19}$

A piperazine derivative, cyclizine lactate (Marzine), was also investigated by Moore, ${ }^{24}$ who found that cyclizine reduced nausea and vomiting to approximately one-half that found using a placebo. Similar reductions in the incidence were 
found by others. ${ }^{12,21}$ However, in a series of 852 cases using meclizine (Bonamine), cyclizine (Marzine), and saline placebos, Tillman ${ }^{31}$ found that there was no apparent advantage in the use of either drug. This perhaps supports Goodman and Gillman's ${ }^{32}$ contention that most of these antihistamines have been statistical successes and the relief gained may be "more obvious to the statistician than to the patient."

Although the antihelmintic phenothiązine has no antihistaminic or C.N.S. depressant action, derivatives of the nucleus possess these as well as many other properties.

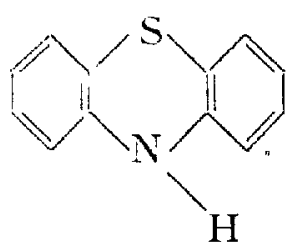

Phenothiazine

Chlorpromazine hydrochloride (Largactil, Thorazine), although not the first phenothiazine derivative discovered, enjoyed the position of being the most thoroughly investigated. Its anti-emetic properties were found to be of the highest order both in apomorphine-induced vomiting in dogs $^{33}$ and in humans following surgery. ${ }^{34}$ Its site of action, and indeed the site of action of all phenothiazines in inhibiting vomiting, is at the C.T.Z. Chlorpromazine lacks antihistaminic activity, does not appear to control motion sickness, and does not prevent vomiting produced by cardiac glycosides. ${ }^{35}$

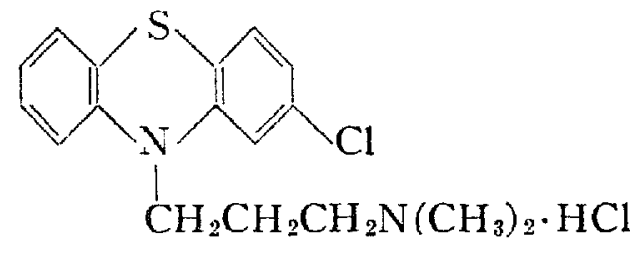

Chlorpromazine $\mathrm{HCl}$

Promethazine hydrochloride (Phenergan) was the first phenothiazine derivative to be discovered and, unlike chlorpromazine, it has strong antihistaminic properties. Its postoperative anti-emetic activity was compared with that of chlorpromazine by Burtles and Peckett ${ }^{7}$ and it was found to be equally as potent and without the disturbing side effects of chlorpromazine, such as hypotension with tachycardia, ${ }^{36}$ vasodilatation, and pain at the site of injection. ${ }^{37}$

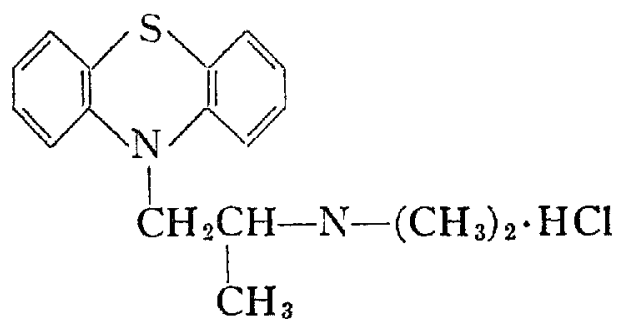

Promethazine $\mathrm{HCl}$

Another phenothiazine compound, prochlorperazine hydrochloride (Stemetil, Compazine) was found to be equally effective as promethazine ${ }^{14}$ but seemed to 
allow for a shorter postoperative recovery time. Boyd ${ }^{38}$ compared the drug with chlorpromazine: both protected against apomorphine, hydergine, and swing but failed to protect against copper sulphate and cedilanid.

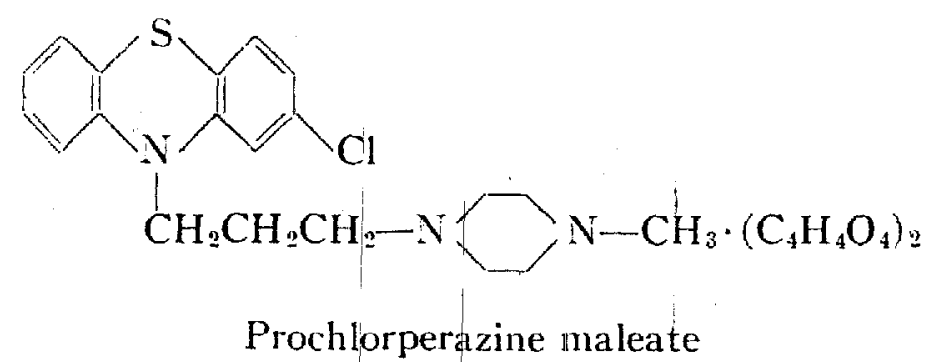

Wang ${ }^{39}$ demonstrated that a fourth derivative of phenothiazine, perphenazine (Trilafon) was from 16.6 to 47.8 times more potent than chlorpromazine in preventing apomorphine-induced vomiting, the higher figure being reached when stronger stimuli were applied. This finding that the drug gains in relative efficacy as the stimulus is increased was confirmed clinically by Phillips $e t a l .^{40}$ In contrast to chlorpromazine's total ineffectiveness in combatting emesis induced by lanatoside $\mathrm{C},{ }^{35}$ perphenazine was quite effective. It has two troublesome side effects: prolonged drowsiness occurring in 38 to 52.6 per cent of Phillips' series ${ }^{40}$. and a Parkinsonian-type reaction ${ }^{40,41}$ which usually clears in 24 hours. Dobkin ${ }^{10}$ found that perphenazine not only reduces postoperative vomiting to one-third compared with controls, but also that the drug is helpful in relieving hiccoughs.

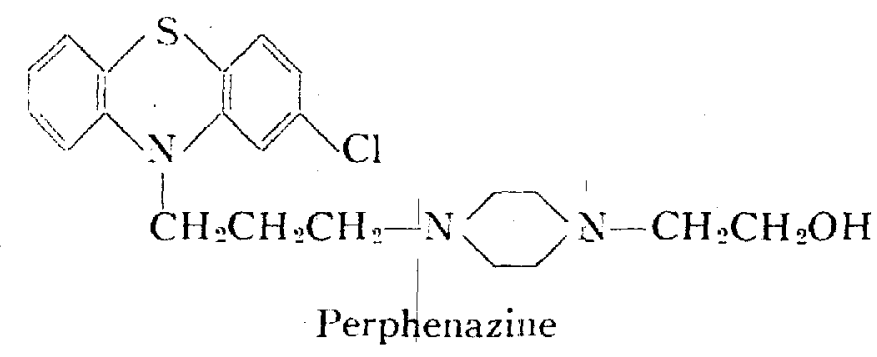

A flourinated phenothiazine derivative, triflupromazine hydrochloride (Vesprin) has been shown to have anti-emetic properties. A significant decrease in postoperative emesis has been found by several authors, ${ }^{41,42,43}$ when it is used both intravenously and intramuscularly. Hypotension was the only undesirable side effect occurring in 8.3 per cent of Davies' series ${ }^{41}$ to 62 per cent of Sheiner's series ${ }^{43}$; this could be relieved simply by elevating the foot of the bed or in some cases using vasopressors. Davies ${ }^{41}$ suggests that the hypotension produced by triflupromazine may be partly cardiogenic in nature, being better relieved by desoxyephedrine than by methoxjamine.

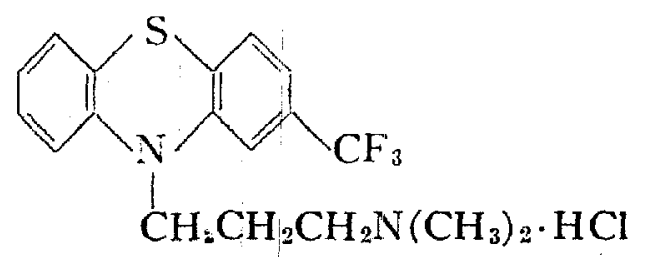

Triflupromazine $\mathrm{HCl}$ 
Pipamazine (Mornidine) will also produce hypotension but only in doses in excess of that necessary to produce statistically significant results as a postoperative anti-emetic. ${ }^{44}$

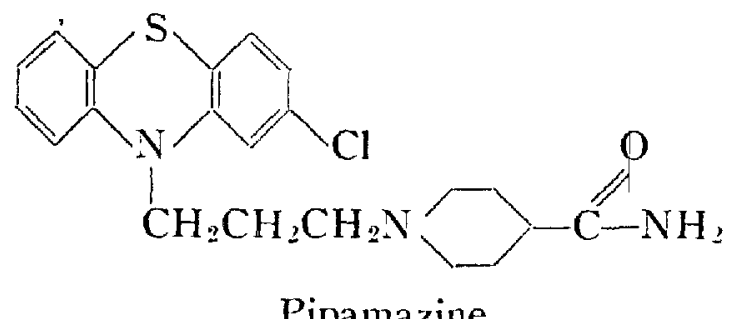

\section{Trimethoxybenzamide (Tigan)}

A substituted benzamide, trimethoxybenzamide hydrochloride (Tigan), was developed as a specific anti-emetic having a direct effect on the C.T.Z. Because it is neither an antihistamine nor a phenothiazine, it was hoped that the undesirable side effects of these two drugs, such as drowsiness and hypotension, might be avoided. An investigation by Schalleck ${ }^{45}$ using dogs found that the drug had about one-tenth the potency of chlorpromazine in preventing apomorphine-induced vomiting and had no depressant effect on the reticularactivating system. While chlorpromazine causes a prolonged fall in blood pressure, which is attributed to an action on the vasoconstrictor centres. in the brainstem, trimethoxybenzamide had much less effect. This fact along with the absence of behavior changes and slowing of EEG patterns suggests that this drug has a more specific action on the centres of controlling emesis.

In an investigation conducted at the Kingston General Hospital using 200 mg. of trimethoxybenzamide hydrochloride intramuscularly following all types of surgery but with certain exclusions (emergency surgery, operations requiring massive transfusions, patients having severe hypotension or bronchospasm, and children under sixteen years) sufficient evidence was not obtained to confirm that this drug was an effective postoperative anti-emetic agent. Using a double blind technique, the active agent or a placebo was injected immediately upon the arrival of the patient in the recovery room and the results noted quarterhourly over a two- to four-hour period. Those who recover promptly after relatively short and minor procedures and are free of hypotension, nausea, vomiting, pain, etc., are discharged quickly while those who have had more extensive procedures and are slower to recover are kept for longer periods, occasionally overnight. The action of the drug is felt to have disappeared by the end of four hours, and further records of nausea and vomiting or the absence thereof are not considered beyond this point. In a total of 500 postoperative patients, a group receiving the placebo gave an incidence of 16.60 per cent whereas a similar series using $200 \mathrm{mg}$. of trimethoxybenzamide had an incidence of 12.45 per cent, a reduction of only 4.15 per cent, which is not statistically significant according to the chi-square test. This finding agrees with Blatchford, ${ }^{44}$ who suggested that because of the lack of side effects it might be employed in larger doses. The series is being continued, therefore, using $400 \mathrm{mg}$. of the drug, and a report of the next 500 cases will be presented at a later date. 
Sheiner ${ }^{46}$ found that the intravenous use of $200 \mathrm{mg}$. of Tigan was useful is. treating laryngospasm or coughing occurring during or after anaesthesia.

\section{Preoperative Use of Anti-emetics}

The routine preoperative use of an anti-emetic is not felt justified and the reasons for this opinion are well stated in an editorial by Keats. ${ }^{47} \mathrm{He}$ feels that 80-90 per cent of patients given a pre-operative antiemetic will have been treated unnecessarily because vomiting will not occur in approximately 70 per cent of these patients and another 10-20 per cent will vomit even though treated. Thus, in order to gain a 10 to 20 per cent decrease in the incidence of nausea and vomiting, 80-90 per cent- of the patients are treated unnecessarily and exposed to the discomfort and unwanted side actions of these drugs. Furthermore, were therg a specific drug without side actions, its routine use would not be justified from the point of view of expense if nothing else, if so little beneficial effect can be anticipated in so few patients.

Lorhan, ${ }^{25}$ on the other hand, felt that the preoperative administration of an anti-emetic would be valuable prior to cataract surgery under local anaesthesia because of the possibility of rupture of the wound, iris prolapse, and occasional loss of ocular content if vomiting or retching occurred. This routine use could perhaps also be extended to complicated ophthalmic surgery under any form of anaesthesia as well as to immobilization of fractures of the facial bones, plastic facial and oral surgery, and other similar forms of surgery where disasters might occur if postoperative vomiting ensued.

\section{Summary and Conclusions}

A brief summary of the anatomy and physiology of the vomiting centre is presented along with a review of the incidence and factors related to postoperative vomiting. The roles of scopolamine, antihistamines, and many of the phenothiazine derivatives now in popular use as presented by several investigators are reviewed. It appears that as the potency and efficacy of a particular postoperative anti-emetic increases, the toxicity and unwanted side effects also increase, an example being perphenazine. Under the conditions of our investigation, trimethoxybenzamide does not appear to reduce postoperative nausea and vomiting to a statistically significant degree although a further trial using a double dose may alter this opinion. The routine preoperative administration of anti-emetics is not justified except in certain cases, such as in cataract and facial surgery where post-operative vomiting might prove disastrous.

The trimethoxybenzamide hydrochloride ( $\mathrm{HCl}$ ) was supplied, and its trial supported, by the Hoffman-LaRoche Company, Montreal.

\section{RÉSUMÉ}

Nous avons résumé brièvement l'anatomie et la physiologie du centre du vomissement, puis nous avons étudié la fréquence des vomissements post-opératoires. et aussi les facteurs qui les influencenti. Nous avons étudié le rôle de la scopola- 
mine, des antihistaminiques et de plusieurs dérivés de la phénothiazine en usage courant actuellement et comme le font plusieurs chercheurs. Il semble qu'à mesure qu'augmentent le pouvoir et l'efficacité d'un antiémétique post-opératoire particulier, augmentent également la toxicité et les effets secondaires indésirables; exemple: la perphénazine. Dans nos conditions d'expérience, la triméthoxybenzamide ne semble pas diminuer les nausées et les vomissements postopératoires de façon appréciable statistiquement, bien qu'un nouvel essai, en employant une double dose, pourrait modifier notre opinion. L'administration de routine, à la suite des opérations, de médications antiémétiques n'est pas justifable, excepté dans les cas de cataracte ou de chirurgie de la face où les vomissements post-opératoires pourraient entrainer un désastre.

\section{REFERENCES}

1. WANG, S. C., \& Borison, H. L. A New Concept of Organization of the Central Emetic Mechanism: Recent Studies on the Sites of Action of Apomorphine, Copper Sulfate and Cardiac Glycosides. Gastroenterology 22: 1 (1952).

2. WANG, S. C. Localization of the Salivatory Centre in the Medulla of the Cat. J. Neurophysiol. 6: 195 (1943).

3. Best, C. H. \& TAYLor, N. B. Physiological Basis for Medical Practice, 7th ed. Baltimore, M.D.: Williams \& Wilkins Co. (1961). P. 701.

4. Hatcher, R. A., \& Weiss, S. Studies on Vomiting. J. Pharmacol. \& Exper. Therap. 22: 139 (1923).

5. Waters, R. M: Present Status of Cyclopropane. Brit. Med. J. 2: 1013 (1936).

6. Dent, S. J.; Ramachandra, V.; \& Stephen, C. R. i Postoperative Vomiting: Incidence, Analysis and Therapeutic Measures in 3000 patients. Anesthesiology 16: 464 (1955).

7. Burtles, R., \& Peckett, B. W. Postoperative Vomiting; Some Factors affecting its Incidence. Brit. J. Anaesth. 29: 114 (1957).

8. Gordon, R. A.; Vandewater, S. L.; Sleath, G. E.; \& Caplin, D. A Study of the Value of Dimenhydrinate and Promethazine Hydrochloride in the Control of Postanaesthetic Vomiting. Canad. Anaesth. Soc. J. 1: 95 (1954).

9. KNAPP, M. R., \& BEEcher, H. K. Post-anaesthetic Nausea, Vomiting and Retching. Evaluation of the Antiemetic Drugs Dimenhydrinate (Dramamine), Chlorpromazine, and Pentobarbital Sodium. J.A.M.A. 160: 376 (1956).

10. Dobrin, A. B. Perphenazine in Clinical Anaesthesia. Canad. Anaesth. Soc. J. 6: 375 (1959).

11. Bellville, J. W.; Bross, I. D. J., \& Howland, W. S. Postoperative Nausea and Vomiting. IV. Factors Related to Postoperative Nausea and Vomiting. Anesthesiology 21: $186(1960)$.

12. Bonica, J. J.; Crepps, W.; Monk, B.; \& Bennett, B. Postoperative Nausea and Vomiting. Western J. Surg. 67: 332 (1959).

13. Marcus, P. S., \& Sheehan, J. S. Treatment of Postoperative Vomiting. Anesthesiology 16: $423(1955)$.

14. Howat, D. D. C. Anti-emetic Drugs in Anaesthesia. Anaesthesia 15: 289 (1960).

15. RoввiE, D. S. Post-anaesthetic Vomiting and Anti-emetic Drugs. Anaesthesia 14: 349 (1959).

16. Tesoriere, H. S. Uses and Abuses of Scopolamine-A Clarification. Anesth. \& Analg. 38: 103 (1959).

17. Goodman, L. S., \& Gilman, A. The Pharmacological Basis of Therapeutics. 2nd ed. New York: MacMillan Company (1955).

18. Moore, D. C.; Anderson, L. G.; Wheeler, G.; \& Schemt, J. The Use of Parenteral Diamamine to Control Postoperative Vomiting: A Report of 1192 Cases. Anesthesiology 13: 354 (1952).

19. Hume, R. B., \& Wriner, W. K. The Use of Dramamine in Control of Postoperative Nausea and Vomiting. Anesthesiology 13: 302 (1952).

20. Camprell, E. H. The Effectiveness of Dramamine in Relieving the Vestibular Reactions Following the Labyrinthine Fenestration Operation. Laryngoscope 59: 1261 (1949). 
21. Wolfe, W. B. The Use of "Dramamine" in the Prevention of Postoperative Nausea and Vomiting. Ann. Surg. 136: 2, 261 (1952).

22. Lofstrum, J. E., \& Nurnberger, C. E. Irradiation Sickness; Histamine Effect Treated with Benedryl; A Preliminary Report. Am. J. Roentgenol. \& Radium Therapy 56: 211 (1946).

23. Bignall, J. R., \& Crofton, J. Antihistaminic Drugs in Treatment of Nausea and Vomiting due to Streptomycin. Brit. Med. J. 1: 13 (1949).

24. Moore, D. C.; Brmenbaugh, L. D.; Picciont, V. F.; Adams, P. A.; \& Lindstrum, C. A. Control of Postoperative Vomiting with Marezine: A Double Blind Study. Anesthesiology 17: 690 (1956).

25. Lontan, P. H. Cyclizine Lactate (Marezine) for Postoperative Control of Nausea and Vomiting after Cataract Surgery. Anaesth. \& Analg. 37: 247 (1958).

26. Robsón, J. M., \& Keele, C. A. Recent Advances in Pharmacology. 2nd ed. London: J. A. Churchill Ltd. (1956). P. 163.

27. White, J. M.; Freedman, D.; McCawley, E. L.; \& Gray, W. D. Effect of Certain Dialkyl-substituted Aminoalkyl-bearing Compounds on Apomorphine-induced Emesis. Federation Proc. 9: 325 (1950).

28. GaY, E. N., \& Caringer, P. E. The Prevention and Treatment of Motion Sickness. Bull. Johns Hopkins Hospital 84: 470 (1949).

29. Caplin, D., \& SMrth, C. A Comparison of the Anti-emetic Effects of Dimenhydrinate, Promethazine Hydrochloride, and Chlorpromazine Following Anaesthesia. Canad? Anaesth. Soc. J. 2: 191 (1955).

30. Kulasavage, R. J., \& McCawley, E. L. Correspondence. J.A.M.A. 145: 429 (195H).

31. Tillman, W. W.; Wise, G. F.; \& CrlawFord, O. B. Evaluation of Marezine-and Bonamine in Lowering the Incidence of Postoperative Vomiting. Anesthesiology 17: $112(1956)$.

32. Goodman, L. S., \& Gilman, A. The Pharmacological Basis of Therapeutics. 2nd ed., 1st printing. New York: MacMillan Co. (1955). P. 664 .

33. Boyd, E. M.; Boyd, C. E.; \& Cassell, W. A. The Anti-emetic Action of Chlorpromazine Hydrochloride. Canad. M.A.J. 70: 276 (1954).

34. Vandewater, S. L., \& Gondon, R. A. Largactil in Anaesthesia. Canad. Anaesth. Soc. J 2: $23(1955)$.

35. Glaviano, V. V., \& Wang, S. C. Dual Mechanism of Anti-emetic Action of 10-( $\gamma$-Dimethylaminopropyl)-2-Chlorophenothiazine hydrochloride (Chlorpromazine) in Dogs. J. Pharmacol. \& Exper. Therap. 114: 358 (1955).

36. DobkIN, A. B.; Kuduff, C. J.; \& WYanT, G. M. Indications for Chlorpromazine (Largactil, Thorazine) in Clinical Anaesthesia. Anaesth. \& Analg. 36: 38 (1957).

37. Dripps, R. D.; Vandam, L. D.; Pierce, E. D.; Oech, S. R.; \& Lurie, A. A. The Use of Chlorpromazine in Anaesthesia and Surgery. Ann. Surg. 142: 774 (1955).

38. Boyd, E. M. Antemetic Action of Proclorperazine. Canad. M.A.J. 76: 286 (1957).

39. Wang, S. C. Perphenazine, a Potent and Effective Antiemetic. J. Pharmacol. \& Exper. Therap. 123: 306 (1958).

40. Phinlips, O. C.; Nelson, A. T.; Lyons, W. B.; Graff, T. D.; Harris, L. C.; \& Frazier, T. M. The Effect of Trilafon on Postanesthetic Nausea, Retching and Vomiting. Anaesth. \& Analg. 39: 38 (1960).

41. Ayn, F. J. Jr. Treatment of Ambulatory and Hospitalized Psychiatric Patients with Trilafon. Diseases of the Nervous System 18: 394 (1957).

42. McIntyre, J. W. R. Ataractics and the Recovery Room with Reference to Triflupromazine, I. Canad. Anaesth. Soc. J. 7: 176 (1960).

43. Sheiner, B. A Preliminary Report on Postoperative Use of Fesprin by Drip Method. Anaesth. \& Analg. 39: 435 (1960).

44. Blatchrond, E. Studies of Anti-emetic Drugs: A Comparative Study of Cyclizine (Marzine), Pipamazine (Mornidine), Trimethobenzamide (Tigan), and Hyoscine. Canad. Anaesth. Soc. J. 8: 159 (1961).

45. Schalleck, W.; Heise, G. A.; Keith, E. F.; \& Bacdon, R. E. Anti-emetic Activity of 4-(2-Dimethylaminoethoxy)-N-(3,4,5-Trimethoxybenzoyl) Benzylamine Hydrochloride. J. Pharmol. \& Exper. Therap. 126: 270 (1959).

46. SHEINER, B. Use of Trimethobenzamide (Tigan) in Anaesthesia. Canad. M.A.J. 83: 1377 (1960).

47. Keats, A. S. Editorial. Anesthesiology 21: 213 (1960). 